\title{
EMISI CO2 PADA BEBERAPA PRAKTEK KULTUR TEKNIS KELAPA SAWIT DI LAHAN GAMBUT
}

Muhammad Arif Yusuf, Suroso Rahutomo*, Winarna

Pusat Penelitian Kelapa Sawit,Jl. Brigjen Katamso No. 51 Medan

*Coresponding author : srahutomo@yahoo.com

\begin{abstract}
Researches to determine the amount of $\mathrm{CO}_{2}$ emission in oil palm plantations on peatland and to know the low emissions technical culture have been conducted in Labuhan Batu district of north Sumatra. Measurement method used is a direct measurement with close chamber technique using a portable gas chromatography. This study showed that proper water management, soil compaction, and planting legume cover crop are the practices of technical culture with low $\mathrm{CO}_{2}$ emissions. Average $\mathrm{CO}_{2}$ emissions in oil palm plantations on peat land which implement proper water management (water table depth was about $50 \mathrm{~cm}$ ), soil compaction before planting, and planting Mucuna bracteata as cover crop were 33.69 tons/ha/year, 35.30 tons/ha/year, and 34.40 tons/ha/year, respectively. Those emissions were lower compared to oil palm plantations with poor water management (water table depth was about $100 \mathrm{~cm}$ ), without compacting the soil when planting, and without a cover crop which were 66.71 tons/ha/year, 65.55 tons/ha/year, and 63.49 tons/ha/year, respectively.
\end{abstract}

Key words: peat land, oil palm, $\mathrm{CO}_{2}$ emission

\begin{abstract}
ABSTRAK
Penelitian untuk mengetahui Besarnya emisi $\mathrm{CO}_{2}$ pada perkebunan kelapa sawit di lahan gambut dan untuk mengetahui praktek kultur teknis yang rendah emisi telah dilakukan di Kabupaten Labuhan Batu, Sumatera Utara. Metode pengukuran yang digunakan adalah pengukuran langsung dengan metode close chamber technique menggunakan Portable Gas Chromatography. Penelitian ini menunjukkan bahwa tata kelola air yang baik, pemadatan tanah, dan penanaman legume cover crop merupakan praktek kultur teknis yang rendah emisi $\mathrm{CO}_{2}$. Rerata emisi $\mathrm{CO}_{2}$ pada kebun kelapa sawit di lahan gambut yang menerapkan tata kelola air yang baik (kedalaman muka air tanah sekitar $50 \mathrm{~cm}$ ), pemadatan tanah sebelum penanaman, dan penanaman Mucuna bracteata sebagai cover crop berturut-turut sebesar 33,69 ton/ha/tahun, 35,30 ton/ha/tahun, dan 34,40 ton/ha/tahun. Nilai rerata emisi $\mathrm{CO}_{2}$ tersebut lebih rendah dibandingkan pada kebun kelapa sawit dengan tata air yang buruk (kedalaman muka air tanah sekitar $100 \mathrm{~cm}$ ), tanpa pemadatan tanah saat penanaman, dan tanpa cover crop yang berturut-turut mencapai 66,71 ton/ha/tahun, 65,55 ton/ha/tahun, dan 63,49 ton/ha/tahun.
\end{abstract}

Kata kunci: lahan gambut, kelapa sawit, emisi $\mathrm{CO}_{2}$

\section{PENDAHULUAN}

Perkembangan industri kelapa sawit saat ini sangat pesat, hal ini terlihat dari permintaan produk industri hilir yang terus meningkat serta tajamnya pertambahan luas areal yang sampai dengan tahun 2013 telah mencapai kurang lebih 10 juta ha (Dirjenbun, 2013). Perkembangan perkebunan kelapa sawit 
kearah lahan gambut mengandung perhatian dunia karena tingginya potensi emisi gas rumah kaca (GRK) yang dihasilkan. Apalagi saat ini Indonesia dituduh sebagai penyumbang emisi GRK terbesar no 3 di dunia. Terbatasnya ketersediaan lahan mineral yang sesuai untuk kelapa sawit telah mendorong perkembangan perkebunan kelapa sawit mengarah ke lahan gambut yang pada tahun 2010 luasannya telah mencapai lebih dari 1,7 juta ha (Tropenbos International Indonesia, 2012). Meskipun dengan biaya biaya investasi dan operasional yang mahal, namun dengan kultur teknis yang tepat produktivitas kelapa sawit di lahan gambut yang tinggi masih bisa dicapai (Winarna et al., 2007). Di sisi lain, perkebunan kelapa sawit dilahan gambut mendapat banyak sorotan terkait potensinya dalam emisi gas rumah kaca (GRK) terutama $\mathrm{CO}_{2}$.

Lahan gambut merupakan ekosistem yang mudah rusak dan juga berperan sebagai cadangan karbon yang sangat penting (Murdiyarso et al., 20014). Gambut memiliki sifat yang fragile sementara kerusakan gambut akan berakibat pada perubahan ekosistem serta mengancam kelestarian fungsi kawasan gambut sebagai tandon air dan penjaga iklim global (Agus et al., 2011). Dengan demikian pemanfaatan lahan gambut untuk budidaya pertanan perlu dilakukan dengan hati-hati. Khusus untuk budidaya kelapa sawit, beberapa praktek kultur teknis yang perlu dilakukan diantaranya adalah: 1) evaluasi kesesuaian lahan, sehingga penggunaan lahan gambut sesuai daya dukungnya, 2) pembukaan lahan tanpa bakar (Darmosarkoro, 2010), 3) pengendalian muka air tanah agar berada pada kedalaman optimal yaitu antara 35 $50 \mathrm{~cm}$ dari permukaan tanah (Othman et al., 2011), 4) Pemupukan, 5) dan peningkatan $\mathrm{pH}$ tanah misalnya dengan pemberian kapur tanaman, 6) pemadatan pada lubang tanam dengan metode hole in hole (Tayeb, 2005), 7) pengendalian hama dan penyakit tanaman secara terpadu, dan 8) pengawasan kebakaran (Darmosarkoro, 2010).

Di berbagai perkebunan kelapa sawit pada lahan gambut di Indonesia, praktek-praktek kultur teknis tersebut telah dilakukan dan telah membantu pencapaian produktivitas yang tinggi. Meskipun demikian, informasi mengenai besaran emisi $\mathrm{CO}_{2}$ pada kebun kelapa sawit di lahan gambut yang menerapkan praktekpraktek kultur teknis tersebut belum banyak tersedia. Penelitian ini dilakukan untuk mengetahui emisi $\mathrm{CO}_{2}$ pada beberapa praktek kultur teknis budidaya kelapa sawit dilahan gambut terutama tata kelola air, pemadatan tanah, dan penanaman legume cover crop. Melalui penelitian ini diharapkan diperoleh paket kultur teknis budidaya kelapa sawit yang tidak hanya diperlukan untuk pencapaian produktivitas tingginamun sekaligus praktek kultur teknis yang rendah emisi $\mathrm{CO}_{2}$.

\section{BAHAN DAN METODE}

\section{Lokasi Penelitian dan Karakteristik Gambut}

Penelitian dilakukan pada beberapa kebun kelapa sawit di Kabupaten Labuhan Batu, Sumatera Utara dengan praktek kultur teknis yang berbeda-beda. Praktek kultur teknis tersebut adalah pengelolaan air yang baik (tipe pengelolaan A), pengelolaan air yang tidak baik (tipe pengelolaan B), pemadatan tanah (tipe pengelolaan $\mathrm{C}$ ), tanpa pemadatan tanah (tipe pengelolaan D), penanaman Legume Cover Crop (LCC) (tipe pengelolaan E), dan tanpa penanaman Legume Cover Crop (tipe pengelolaan F).

Karakteristik lahan gambut pada tipe pengelolaan A antara lain tinggi muka air tanah sedalam $\pm 50 \mathrm{~cm}$ dari permukaan tanah, pertumbuhan tanaman cukup jagur dan homogen, tata kelola air cukup baik (terdapat stop log di beberapa titik pada saluran drainase untuk mempertahankan 
tinggi muka air), kedalaman gambut berkisar antara 3-4 m, dan tanpa cover crop. Karakteristik lahan gambut pada tipe pengelolaan $\mathrm{B}$ antara lain tinggi muka air tanah > $100 \mathrm{~cm}$ dari permukaan tanah, pertumbuhan tanaman cukup jagur dan homogen, tata kelola air buruk (tidak terdapat stop log pada saluran drainase sehingga tinggi muka air tanah tidak dapat dikontrol pada kedalaman ideal), kedalaman gambut berkisar antara 3-4 m, dan tanpa cover crop. Secara rinci perbedan antara tipe perlakuan A dan B disajikan pada tabel 1.

Karakteristik lahan gambut pada tipe pengelolaan $\mathrm{C}$ antara lain adalah adanya pemadatan yang dilakukan secara mekanis dengan menggunakan alat berat pada saat persiapan lahan sebelum penanaman, tinggi muka air tanah \pm 100 $\mathrm{cm}$ dari permukaan tanah, tata air tidak baik (tidak terdapat stop log pada saluran drainase sehingga tinggi muka air tanah > $100 \mathrm{~cm}$ ). Karakteristik lahan gambut pada tipe pengelolaan D antara lain adalah tidak dilakukan pemadatan yang dilakukan secara mekanis dengan menggunakan alat berat pada saat persiapan lahan, tinggi muka air tanah $\pm 100 \mathrm{~cm}$ dibawah permukaan tanah, tata air tidak baik (tidak terdapat stop log pada saluran drainase sehingga tinggi muka air tanah $>100 \mathrm{~cm}$ ).

Karakteristik lahan gambut pada tipe pengelolaan $\mathrm{E}$ antara lain penanaman Mucuna bracteata (LCC) jenis Mucuna bracteata, tinggi muka air kurang lebih 50$60 \mathrm{~cm}$ dibawah permukaan tanah, tata kelola air cukup baik (terdapat stop log di beberapa titik pada saluran drainase untuk mempertahankan tinggi muka air). Sedangkan karakteristik lahan gambut pada tipe pengelolaan $\mathrm{F}$ antara lain tidak ada penanaman LCC, tata kelola air cukup baik (terdapat stop $\log$ di beberapa titik pada saluran drainase untuk mempertahankan tinggi muka air). Kedua lahan tersebut sama-sama mengalami pemadatan yang cukup intensif pada saat persiapan lahan sebelum penanaman. Kedalaman gambut pada kedua perlakuan yaitu 3-4 meter. Perbedaan karakteristik lahan antara tipe pengelolan E dan F lebih jelas tersaji pada Tabel 1.

Tabel 1. Karakteristik lahan pada tipe pengelolaan A, B, C, D, E, dan F.

\begin{tabular}{|c|c|c|c|c|c|c|c|}
\hline No & $\begin{array}{c}\text { Pengelolaan } \\
\text { lahan }\end{array}$ & $\begin{array}{c}\text { Tipe } \\
\text { Pengelolaan } \\
\text { A } \\
\end{array}$ & $\begin{array}{c}\text { Tipe } \\
\text { Pengelolaan } \\
\text { B } \\
\end{array}$ & $\begin{array}{c}\text { Tipe } \\
\text { Pengelolaan } \\
\text { C } \\
\end{array}$ & $\begin{array}{c}\text { Tipe } \\
\text { Pengelolaan } \\
\text { D } \\
\end{array}$ & $\begin{array}{c}\text { Tipe } \\
\text { Pengelolaan } \\
\text { E } \\
\end{array}$ & $\begin{array}{c}\text { Tipe } \\
\text { Pengelolaan } \\
F \\
\end{array}$ \\
\hline 1 & $\begin{array}{l}\text { Tinggi } \\
\text { muka air } \\
\text { Tanah }\end{array}$ & $\pm 50 \mathrm{~cm}$ & $>100 \mathrm{~cm}$ & $\pm 100 \mathrm{~cm}$ & $\pm 100 \mathrm{~cm}$ & $50-60 \mathrm{~cm}$ & $50-60 \mathrm{~cm}$ \\
\hline 2 & Tata air & Baik & tidak baik & $\begin{array}{l}\text { Kurang } \\
\text { Baik }\end{array}$ & $\begin{array}{l}\text { Kurang } \\
\text { Baik }\end{array}$ & Baik & Baik \\
\hline 3 & $\begin{array}{l}\text { Umur } \\
\text { tanaman }\end{array}$ & $\begin{array}{l}\mathrm{TBM}(<3 \\
\text { tahun) }\end{array}$ & $\begin{array}{l}\mathrm{TBM}(<3 \\
\text { tahun) }\end{array}$ & $\begin{array}{l}\text { TM (10 } \\
\text { tahun) }\end{array}$ & $\begin{array}{l}\mathrm{TM}(10 \\
\text { tahun) }\end{array}$ & $\begin{array}{l}\text { TBM (< } \\
\text { 3tahun) }\end{array}$ & $\begin{array}{l}\text { TBM (< } \\
\text { 3tahun) }\end{array}$ \\
\hline 4 & $\begin{array}{l}\text { Land } \\
\text { Cover } \\
\text { crops }\end{array}$ & - & - & - & - & $\begin{array}{l}\text { Mucuna } \\
\text { bracteata }\end{array}$ & - \\
\hline 5 & $\begin{array}{l}\text { Pemadata } \\
\mathrm{n}\end{array}$ & - & - & Mekanis & - & Mekanis & Mekanis \\
\hline
\end{tabular}

*Faktor-faktor lain yang tidak ditampilkan kurang lebih sama 


\section{Pengukuran Emisi $\mathrm{CO}_{2}$}

Emisi $\mathrm{CO}_{2}$ diukur secara langsung dengan metode close chamber technique yang diadopsi dari IAEA (1993). Pengambilan contoh $\mathrm{CO}_{2}$ dilakukan secara manual dengan menggunakan boks terbuat dari kaca mika dengan kaki-kaki terbuat dari almunium. Dimensi panjang $\mathrm{x}$ lebar $\mathrm{x}$ tinggi masing-masing boks adalah $60 \mathrm{~cm} \mathrm{x}$ $60 \mathrm{~cm} \times 30 \mathrm{~cm}$. Boks dilengkapi kipas dengan sumber energi berasal dari baterai elemen kering. Kipas tersebut berfungsi untuk menghomogenkan konsentrasi gas dalam box.

Jarum suntik dengan volume $10 \mathrm{ml}$ digunakan untuk mengambil contoh gas. Dalam satu kali pengamatan dilakukan pengambilan 4 contoh gas dengan interval waktu 10, 20, 30, dan 40 menit. Pengambilan sampel dilakukan pada pukul 06.00-07.00 pagi, 13.00-14.00 siang, dan 19.00-20.00 malam. Contoh gas dalam jarum suntik $10 \mathrm{ml}$ yang sudah terkumpul kemudian dianalisis konsentrasinya menggunakan portable gas chromatography.

\section{HASIL DAN PEMBAHASAN}

\section{Emisi $\mathrm{CO}_{2}$ pada Kondisi Drainase Berbeda}

Drainase adalah prasyarat untuk pengembangan pertanian di lahan gambut yang pada umumnya memiliki masalah drainase tanah akibat jumlah air yang melimpah. Menurut Jali (2004), drainase mampu membuat kondisi lahan gambut menjadi potensial redoks tingi dengan aktifitas mikroba yang bermacam-macam dan mineralisasi nitrogen yang akan menstimulasi oksidasi gambut dan pada akhirnya berkontribusi terhadap emisi $\mathrm{CO}_{2}$. Terdapat perbedaan emisi $\mathrm{CO}_{2}$ yang dihasilkan oleh lahan dengan tata air yang baik (kedalaman muka air tanah $\pm 50 \mathrm{~cm}$ ) dan lahan dengan tata air yang kurang baik (kedalaman muka air tanah > $100 \mathrm{~cm}$ ) (Gambar 1). Hasil pengukuran emisi $\mathrm{CO}_{2}$ pada tipe pengelolaan A rata-rata sebesar
33,69 ton/ha/tahun, sedangkan pada tipe pengelolaan lahan $\mathrm{B}$ rata-rata sebesar 66,71 ton/ha/tahun. Hal ini sejalan dengan penelitian Melling dan Goh (2010) serta Setyanto et al. (2010) yang menyatakan adanya hubungan antara kedalaman muka air tanah dan emisi $\mathrm{CO}_{2}$ di lahan gambut, dimana hingga kedalaman tertentu penurunan muka air tanah akan menyebabkan peningkatan emisi $\mathrm{CO}_{2}$. Othman et al. (2011) berpendapat bahwa menjaga ketinggian muka air tanah pada kedalaman 30-50 cm memiliki pengaruh yang baik terhadap pertumbuhan tanaman kelapa sawit dan dapat mencegah emisi $\mathrm{CO}_{2}$ yang berlebihan.

Rendahnya emisi $\mathrm{CO}_{2}$ yang dihasilkan oleh lahan gambut dengan tata air yang baik dibandingkan dengan tata air yang buruk merupakan indikasi adanya respirasi tanah yang terbatasi (Meilling dan Joo, 2010). Perakaran kelapa sawit banyak dijumpai pada kedalaman 1 meter, Selain itu pada kedalaman tersebut, dekomposisi berjalan sangat cepat, namun seiring dengan muka air tanah yang tinggi, bakteri anaerobik semakin berkurang dan dekomposisi berjalan lambat sehingga emisi $\mathrm{CO}_{2}$ yang dihasilkan lebih kecil. Handayani dan Noordwitjk (2009) juga melaporkan bahwa emisi $\mathrm{CO}_{2}$ dari gambut dengan mengukur respirasi akar.

Penurunan muka air tanah yang semakin dalam memicu peningkatan jumlah emisi $\mathrm{CO}_{2}$ yang dilepaskan oleh lahan gambut. Penurunan muka air tanah tersebut akan meningkatkan oksidasi pada permukaan gambut, yang kemudian berpengaruh terhadap respirasi akar dan laju dekomposisi gambut. Hal ini juga menyebabkan terjadinya amblesan (Rieley et al., 2008). Laju amblesan gambut mempunyai hubungan yang erat dengan emisi $\mathrm{CO}_{2}$ ke atmosfir. Othman et al. (2011) menyatakan bahwa setiap terjadi amblesan lahan gambut (bulk density ratarata sebesar $0,17 \mathrm{~g} / \mathrm{cm}^{3}$ dan fraksi oksidasi karbon $40 \%$ ) sebesar $2-4 \mathrm{~cm}$, berarti telah 
terjadi pelepasan emisi $\mathrm{CO}_{2}$ sebesar 32-63 ton/ha/tahun dari lahan gambut.

Hasil pengukuran emisi $\mathrm{CO}_{2}$ pada pagi, siang dan malam hari baik tipe pengelolaan $\mathrm{A}$ maupun tipe pengelolan $\mathrm{B}$ memiliki pola yang sama. Emisi $\mathrm{CO}_{2}$ yang dihasilkan pada siang hari memiliki nilai paling tinggi dibandingkan dengan pengukuran pagi ataupun malam hari. Perbedaan nilai emisi ini disebabkan oleh variasi suhu permukaan tanah pada setiap waktu pengukuran. Pada waktu siang hari suhu permukaan tanah memiliki nilai paling tinggi dibandingkan dengan waktu pengukuran lainnya. Hal ini sejalan dengan Nyakanen et al., (1995) yang menyatakan bahwa temperatur merupakan salah satu faktor utama yang mempengaruhi besaran nilai emisi di lahan gambut.

\section{Emisi $\mathrm{CO}_{2}$ pada Kondisi Pemadatan} Tanah Berbeda

Tanah gambut memiliki porositas yang tinggi dan bulk density yang rendah. Pemadatan secara mekanik pada jalan panen dan baris tanaman di kebun kelapa sawit dapat meningkatkan bulk density tanah (Tayeb, 2005). Tanah gambut yang mengalami peningkatan bulk density akan menjadi media yang lebih baik untuk pertumbuhan akar. Hasil pengukuran emisi $\mathrm{CO}_{2}$ pada lahan gambut yang telah mengalami pemadatan menunjukkan nilai rata-rata sebesar 40,59 ton/ha/tahun, sedangkan rata-rata emisi $\mathrm{CO}_{2}$ yang dihasilkan pada lahan tanpa pemadatan sebesar 61,75 ton/ha/tahun. Dari hasil pengukuran tersebut, terlihat bahwa pemadatan tanah gambut sangat berpengaruh pada emisi yang dihasilkan. Dengan adanya pemadatan, maka nilai bulk density tanah gambut akan meningkat. Nilai bulk density yang tingi akan meningkatkan pori mikro yang mengakibatkan retensi kelembaban meningkat dan dapat menambah situs anaerobik walaupun pada kondisi kadar air yang menurun (Melling et al., 2005).

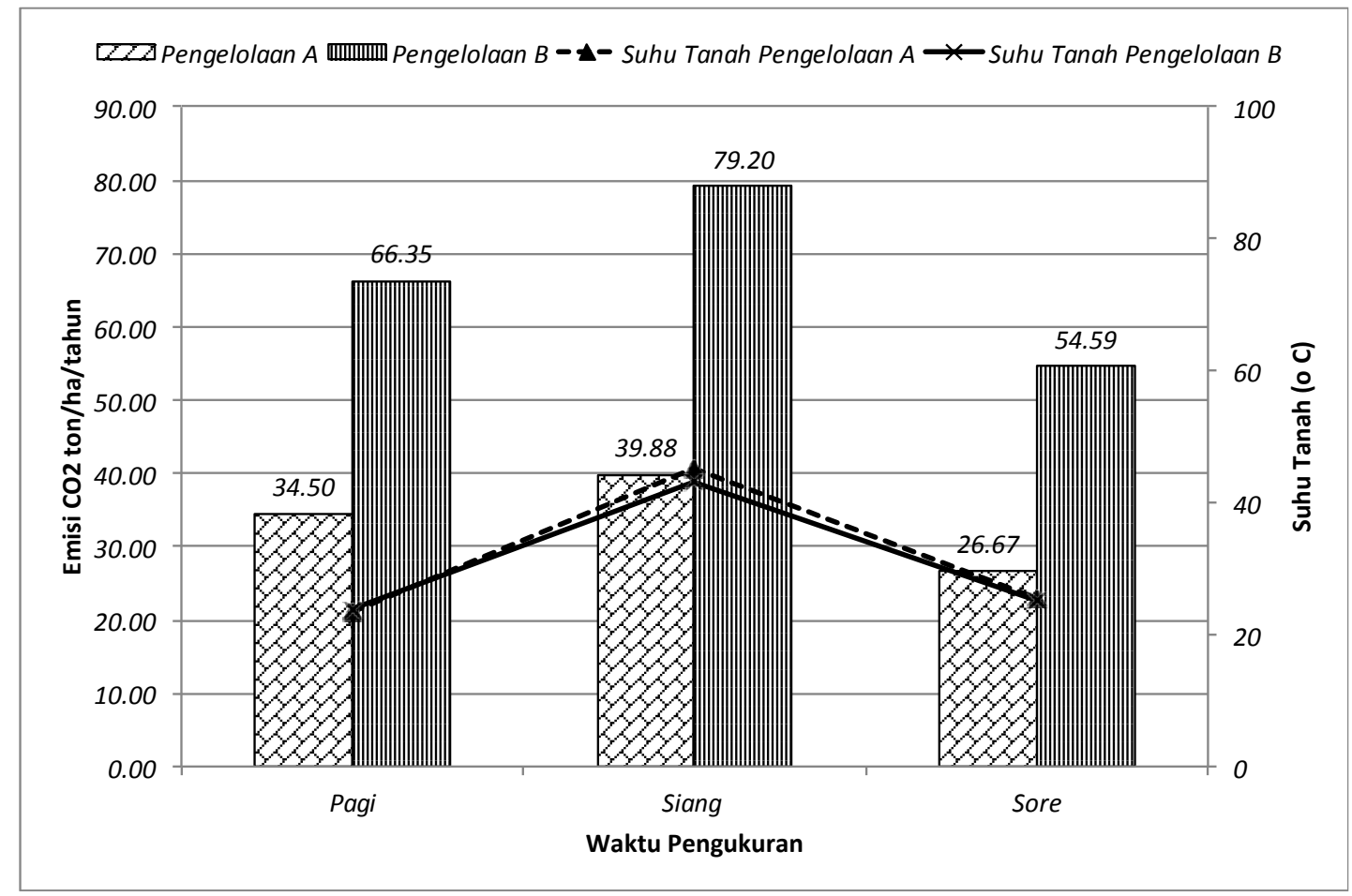

Gambar 1. Hasil Pengukuran Emisi $\mathrm{CO}_{2}$ pada pengelolaan A dan pengelolaan B 
Kondisi anaerobik menyebabkan respirasi akar tertekan, aktifitas respirasi mikroba menjadi terganggu dan dekomposisi tanah gambut pun berjalan lambat. Besarnya emisi $\mathrm{CO}_{2}$ sangat dipengaruhi oleh tingkat dekomposisi tanah gambut (Othman et al., 2011) dengan demikian maka emisi $\mathrm{CO}_{2}$ yang dihasilkan lahan gambut yang telah mengalami pemadatan menjadi lebih sedikit. Hasil pengukuran emisi $\mathrm{CO}_{2}$ pada waktu pagi, siang dan malam hari di tipe pengelolaan $\mathrm{C}$ memiliki pola yang berbeda dengan tipe pengelolan $\mathrm{B}$. Emisi $\mathrm{CO}_{2}$ yang dihasilkan pada siang hari di tipe pengelolaan $\mathrm{D}$ memiliki nilai paling tinggi dibandingkan dengan pengukuran pagi ataupun malam hari. Perbedaan nilai emisi ini disebabkan oleh variasi suhu permukaan tanah pada setiap waktu pengukuran. Pada waktu siang hari suhu permukaan tanah memiliki nilai paling tinggi dibandingkan dengan waktu pengukuran lainnya. Sedangkan pada tipe pengelolan $\mathrm{C}$, emisi $\mathrm{CO}_{2}$ paling tinggi terdapat pada pengukuran pagi hari. Hal ini diduga adanya pengaruh dari pemadatan tanah yang mengakibatkan perubahan sifat fisik dan distribusi pori tanah.

\section{Emisi $\mathrm{CO}_{2}$ pada Kondisi LCC Berbeda}

Penggunaan Legume Cover Crop (LCC) pada kebun kelapa sawit sudah lama dilaksanakan, terutama pada pertanaman kelapa sawit muda. Penggunan kacangan ini bertujuan untuk menanggulangi erosi permukaan dan pencucian hara tanah, fiksasi nitrogen untuk memperkaya hara $\mathrm{N}$ tanah dan untuk menekan pertumbuhan gulma. Pengukuran emisi $\mathrm{CO}_{2}$ pada lahan yang ditamani LCC (tipe pengelolaan E) dan tanpa ditanami LCC (tipe pengelolan F), menunjukkan bahwa emisi yang dihasilkan pada lahan yang ditanami LCC memiliki nilai yang lebih kecil dibandingkan pada lahan tanpa penanaman LCC. Lahan yang ditanami LCC memiliki emisi $\mathrm{CO}_{2}$ sebesar 30,43 ton/ha/tahun, sedangkan lahan tanpa penanaman LCC memiliki emisi $\mathrm{CO}_{2}$ sebesar 56,85 ton/ha/tahun.

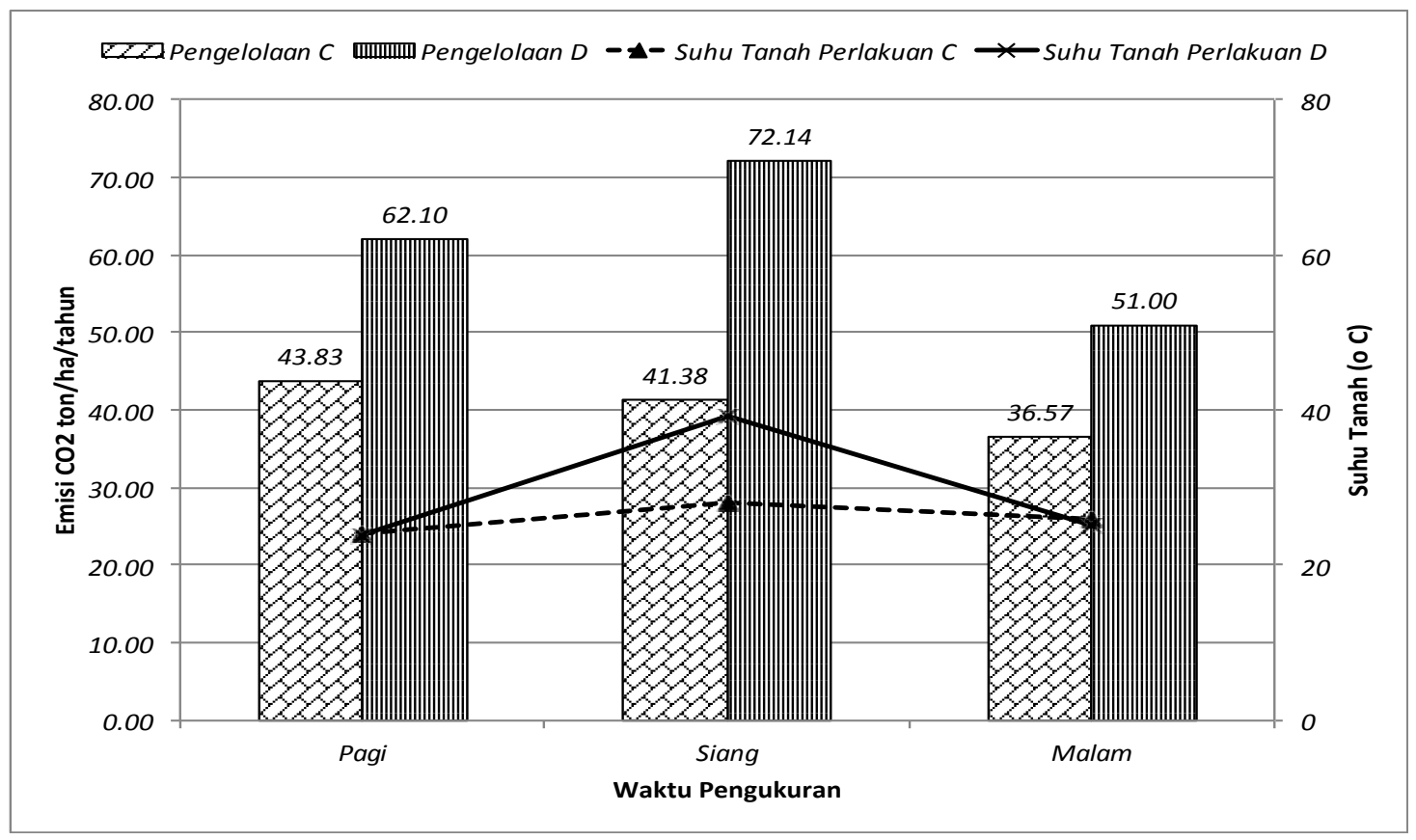

Gambar 2. Hasil Pengukuran Emisi $\mathrm{CO}_{2}$ pada Pengelolaan Lahan Tipe C dan D 


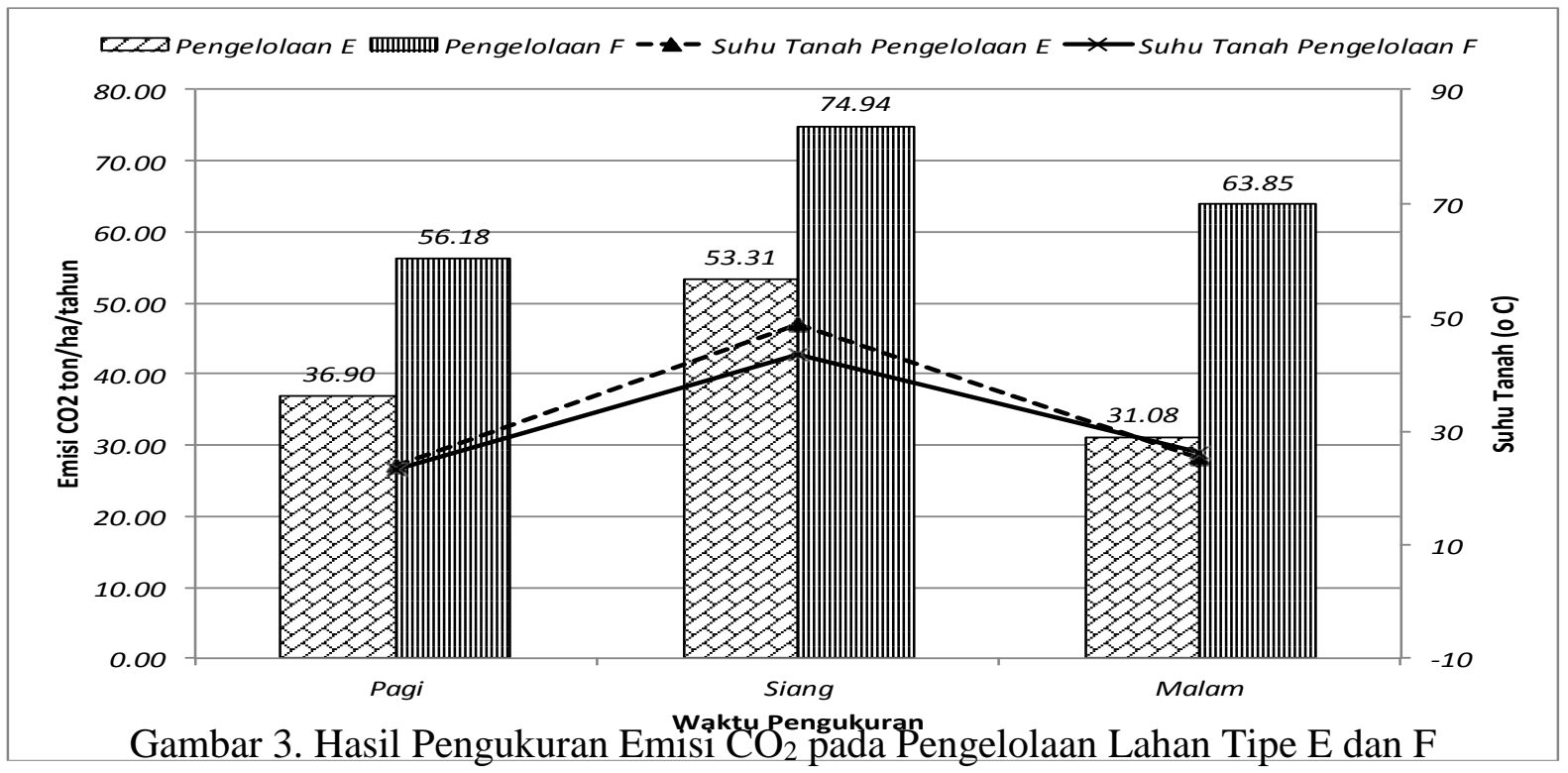

Salah satu faktor lingkungan yang paling utama dalam mempengaruhi besarnya emisi dari lahan gambut adalah temperatur (Nyakanen et al., 1995). Dekomposisi bahan organik di tanah gambut tropika umumnya berlangsung cepat terkait dengan temperatur permukaan gambut yang tinggi sepanjang tahun (Takahashi dan Yonetani, 1997). Penanaman LCC umumnya menurunkan suhu di permukaan lahan gambut menjadi lebih rendah. Suhu yang lebih rendah menyebabkan oksidasi menjadi lebih rendah, sehinga laju dekomposisi menjadi lebih lambat dan emisi $\mathrm{CO}_{2}$ yang dihasilkan lebih sedikit. Lahan yang relatif gundul dan diberakan, kemungkinan besar akan meningkatkan temperatur tanah yang kemudian akan berpengaruh pada dekomposisi tanah gambut (Melling dan Joo, 2010).

Hasil pengukuran emisi $\mathrm{CO}_{2}$ pada pagi, siang dan malam hari baik tipe pengelolaan $\mathrm{E}$ maupun tipe pengelolan $\mathrm{F}$ memiliki pola yang sama. Emisi $\mathrm{CO}_{2}$ yang dihasilkan pada siang hari memiliki nilai paling tinggi dibandingkan dengan pengukuran pagi ataupun malam hari. Perbedaan nilai emisi ini disebabkan oleh variasi suhu permukaan tanah pada setiap waktu pengukuran. Pada waktu siang hari suhu permukaan tanah memiliki nilai paling tinggi dibandingkan dengan waktu pengukuran lainnya. Hal ini sejalan dengan Nyakanen et al., (1995) yang menyatakan bahwa temperatur merupakan salah satu faktor utama yang mempengaruhi besaran nilai emisi di lahan gambut.

\section{SIMPULAN}

Penelitian ini menunjukkan bahwa tata kelola air dengan mempertahankan muka air tanah sedalam $50 \mathrm{~cm}$ memiliki rerata emisi $\mathrm{CO}_{2}$ sebesar 33,69 ton/ha/tahun, lebih rendah dibandingkan dengan rerata emisi $\mathrm{CO}_{2}$ pada lahan gambut dengan kedalaman muka air tanah $100 \mathrm{~cm}(66,71$ ton/ha/tahun). Pada kebun kelapa sawit di lahan gambut yang menerapkan pemadatan tanah pada saat penanaman, rerata emisi $\mathrm{CO}_{2}$ adalah 35,30 ton/ha/tahun, lebih rendah dibandingkan dengan rerata emisi $\mathrm{CO}_{2}$ pada kebun kelapa sawit tanpa pemadatan tanah saat penanaman yang mencapai 65,55 ton/ha/tahun. Selanjutnya, rerata emisi $\mathrm{CO}_{2}$ pada kebun kelapa sawit di lahan gambut yang menanam Mucuna bracteata sebagai cover crop adalah 34,40 ton/ha/tahun, lebih rendah dibandingkan 
rerata emisi $\mathrm{CO}_{2}$ pada kebun kelapa sawit tanpa cover crop yang mencapai 63,49 ton/ha/tahun. Dengan demikian, tata kelola air yang baik, pemadatan tanah pada saat penanaman, dan penanaman Mucuna bracteata sebagai cover crop merupakan praktek kultur teknis yang rendah emisi $\mathrm{CO}_{2}$.

\section{DAFTAR PUSTAKA}

Agus, F., K. Hairiah, A. Mulyani. 2011. Petunjuk praktis Pengukuran cadangan karbon tanah gambut. World Agroforestry Centre, ICRAF Southeast Asia dan Balai Besar Penelitian dan Pengembangan Sumberdaya Lahan Pertanian, Indonesia. ISBN 978-979-3198-57-6. 58 pp.

Darmosarkoro, W. 2010. Facing climate change issue on oil palm industry, in: Proceedings of International Oil Palm Conference 2010, Yogyakarta. p. $78-89$

Handayani, E. and M.V. Noordwijk. 2009. Carbon dioxide $\left(\mathrm{CO}_{2}\right)$ and methane $\left(\mathrm{CH}_{4}\right)$ emission on oil palm peatland with various peat thickness and plant age. http://www.forestclimatechange. org/fileadmin/tropicalworkshop/Posters.

Jal, D. 2004. Nitrogen mineralization in the tropical peat swamps, in: proceedings of the 12th International Peat Congress, Tampere, P. 644-652.

Melling, L. and K.J. Goh. 2010. Greenhouse gas emission from tropical peatland - myths, facts and uncertainties in: Proceedings of International Oil Palm Conference 2010, Yogyakarta. p. 90-97

Melling, L., R. Hatano, and K.J. Goh. 2005. Methane fluxes from three ecosystem in tropical Peatland of Sarawak Malaysia. Soil Biology \& Biochemistry 37 (2005) 1445-1453

Murdiyarso, D., U. Rosalina, K. Hairiah, L. Muslihat, I.N.N. Suryadiputra, A. Jaya. 2004. Pendugaan cadangan karbon pada lahan gambut. Wetlands International, Indonesia.

Nyakanen, H., Alm, J., Lang, K., Silvola, T., Martikainen, P.J., 1995. Emissions of $\mathrm{CH}_{4}, \mathrm{~N}_{2} \mathrm{O}$, and $\mathrm{CO}_{2}$ from a virgin fen drained for grassland in Finland. Journal of Biogeography 22, 351-357.

Othman, H., A.T. Mohammed, F.M. Darus, M.H. Harun, and M.P. Zambri. 2011. Best management practices for oil palm cultivation on peat; Groung water-table maintanance in relation to peat subsidance and estimation of $\mathrm{CO}_{2}$ emissions at Sessang, Sarawak. Journal of Oil Palm Research Vol 23 August 2011 p. 1078-1086.

Rieley, J.O., R.A.J.Wüst., J. Jauhiainen., S.E. Page., H. Wösten., A.Hoijer.,F. Siegert., S. Limin., $\mathrm{H}$. Vasander., and M. Stahlhut. 2008. Tropical peatlands: carbon store, carbon gas emissions and contribution to climate change processes. In: M. Strack (ed.), Peatlands and Climate Change. Publisher International Peat Society, Vapaudenkatu, Jyväskilä, Finland. 149-181.

Setyanto, P., H.L. Susilawati, S. Rahutomo, L. Erningpraja. 2010. $\mathrm{CO}_{2}$ emission from peat under oil palm plantation in: Proceedings of International Oil Palm Conference 2010, Yogyakarta. p. 237-244. 
Statistik Perkebunan Indonesia 2012-2014 : Kelapa Sawit. Direktorat Jenderal Perkebunan, Kementerian Pertanian, 2013.

Takahashi, H., and Y. Yonetani. 1997. Studies on microclimate and hydrology of peat swamp forest in Central Kalimantan, Indonesia. Dalam: J.O. Rieley., and S.E. Page (eds.) Biodiversity and sustainability of tropical peatland. Proceeding of the International Symposium on Tropical Peatlands. Palangka Raya, Indonesia. Samara Publisher, Cardigan, UK. 179-187

Tayep, M.D. 2005. Technologies for planting oil palm on peat. MPOB, Bangi. 83 pp.

Tropenbos International Indonesia. 2012. Kajian Penggunaan lahan gambut di Indonesia. Disampaikan pada pada seminar "lahan Gambut: Maslahat atau Mudharat". Forum Wartawan Pertanian. Jakarta, 15 Maret 2012.

Winarna, D. Wiratmoko, E.S. Sutarta, S. Rahutomo, dan Sujadi. 2007. Potensi dan kendala lahan rawa pasang surut untuk budidaya tanaman kelapa sawit. Prosiding Seminar Nasional Pertanian Lahan Rawa. Kuala Kapuas, 3-4 Agustus 2007. p: $223-235$. 